\title{
The association between hydroxychloroquine treatment and cardiovascular morbidity among rheumatoid arthritis patients
}

\author{
Michael Shapiro ${ }^{1,2}$ and Yair Levy ${ }^{1,2}$ \\ ${ }^{1}$ Department of Medicine E, Meir Medical Center, Kfar Saba, Israel \\ ${ }^{2}$ Sackler Faculty of Medicine, Tel Aviv University, Tel Aviv, Israel \\ Correspondence to: Yair Levy, email: yairlevi@post.tau.ac.il
}

Keywords: hydroxychloroquine, cardiovascular morbidity, rheumatoid arthritis

Received: September 04, 2017 Accepted: October 05, $2017 \quad$ Published: December 15, 2017

Copyright: Shapiro et al. This is an open-access article distributed under the terms of the Creative Commons Attribution License 3.0 (CC BY 3.0), which permits unrestricted use, distribution, and reproduction in any medium, provided the original author and source are credited.

\section{ABSTRACT}

Objectives: To examine the independent effect of hydroxychloroquine (HCQ) treatment on cardiovascular morbidity among RA patients.

Materials and Methods: A retrospective cohort study of RA patients treated at Meir medical center between 2003-2013 was conducted. Patients were divided into two groups, those who had been treated with HCQ during the course of their disease and those who had never received it. The two groups were compared for possible confounding factors. Study endpoints included arterial and venous thrombotic events.

Results: A total of 514 suitable RA patients were identified, 241 HCQ-treated and 273 non-treated patients. Of the HCQ-treated patients, $32(13.3 \%)$ suffered from cardiovascular events compared to $104(38.1 \%)$ of the non-treated group. HCQ treatment had a significant protective effect for all cardiovascular events examined $(H R=0.456 \mathrm{CI} 0.287$ to 0.726$)$ as well as arterial events alone $(H R=0.461$ CI 0.274 to 0.778 ). A dose of $400 \mathrm{mg} \mathrm{HCQ}$ per day demonstrated a protective effect for any cardiovascular event ( $\mathrm{HR}=0.432 \mathrm{CI} 0.243$ to 0.768$)$, while the lower dose of $200 \mathrm{mg}$ per day showed no significant protective effect.

Conclusions: The use of HCQ is independently associated with decreased risk for cardiovascular morbidity among RA patients, particularly with a higher dose of $400 \mathrm{mg}$ per day. This newly demonstrated effect of HCQ should be considered in the overall management of RA.

\section{INTRODUCTION}

Rheumatoid arthritis is a chronic inflammatory disease affecting approximately 1.3 million adults in the US alone [1]. The hallmark of the disease is an inflammatory process affecting peripheral joints, leading to deformity. In addition, about $40 \%$ of patients will incur various systemic manifestations leading to severe morbidity and mortality [2]. The risk factors for systemic disease include high levels of RF and anti-CCP markers and smoking [3].

The increased risk for cardiovascular disease (CVD) is one of the most severe systemic manifestations of RA. Several large studies showed that RA patients have 1.5 times the risk for myocardial infarctions (MI) and twice the risk for stroke than the general population $[4,5]$. A large study of about 12 thousand RA patients compared to 58 thousand matched controls showed a $30 \%$ higher proportion of ischemic heart disease among RA patients [6].

For these patients, traditional cardiovascular disease (CVD) risk factors, such as diabetes, dyslipidemia and hypertension (HTN) play a significant role [4]. However, the increased CVD risk is attributed to systemic inflammation that is thought to promote accelerated atherosclerosis [5, 7, 8]. Moreover, there is strong evidence showing that inflammatory markers, such as $\mathrm{CRP}$ are independently associated with CV mortality and morbidity in RA [9].

In 2010, The European League Against Rheumatism) EULAR) published recommendations for cardiovascular risk management in patients with RA. 
The recommendations included recognition of RA as a condition with higher risk for CVD, especially for patients with a disease duration of more than 10 years, who have positive RF or anti-CCP titers and present with extraarticular manifestations. Additional recommendations included adequate control of disease activity, treatment with statins and ACE inhibitors and smoking cessation [10].

The current recommended therapy for RA is early, aggressive treatment at diagnosis in order to reduce the inflammatory process and prevent joint deformity. First line treatment usually combines limited steroid therapy and traditional disease-modifying anti-rheumatic drugs (DMARDS). The most commonly used drugs include methotrexate (MTX), hydroxychloroquine (HCQ) and sulfasalazine. The second line therapy includes a growing variety of new biological agents [11, 12].

Hydroxychloroquine, an anti-malarial drug, is one of the oldest drugs used in rheumatology. It is widely used as a first line therapy to treat RA and systemic lupus erythematosus (SLE), usually concomitant with other therapies. Lately, this drug has been losing favor and is frequently omitted, especially when biological agents are added [11].

Several studies examined the effects of HCQ on cardiovascular risk factors. A retrospective study, including over $600 \mathrm{RA}$ patients treated with various combinations of DMARDs compared to prednisone alone, found a protective effect against cardiovascular morbidity with the combined therapy of HCQ, MTX and sulfasalazine. Due to its design and size, the study was unable to show a significant effect of HCQ treatment alone [13]. Three studies examining the effect of HCQ on lipid profile among patients with RA and SLE found a significant decrease in LDL and triglyceride levels, as well as an improvement in the LDL/HDL ratio [14-16]. HCQ was also found to have a protective effect from developing diabetes among RA patients [17]. Several studies on HCQ among SLE patients found a protective effect against atherosclerosis and venous thrombosis events [18]. In light of these results, this study was conducted to evaluate the effect of HCQ on cardiovascular morbidity among patients with RA.

\section{RESULTS}

The patients' characteristics for the treated vs the non-treated group are presented in Table 1.

A total of 514 RA patients treated at Meir Medical Center from 2003 through 2013 were identified. Among these, 241 patients $(46.9 \%)$ were treated with HCQ and $273(53.1 \%)$ had never been treated with this medication.

As shown, both groups were predominately female (about 77\%) and the HCQ-treated group were younger than the non-treated group $(P<0.001)$. Furthermore, the HCQ-treated group had significantly shorter RA disease duration $(P=0.002)$ and lower average CRP value $(P=0.03)$ compared to the treated group. The average anti-CCP level was not different between the groups. However, information regarding the anti- CCP levels was available only for 55 patients $(10.7 \%)$, as the test was approved in Israel for all RA patients only in 2012.

Most of the cardiovascular risk factors were similar between the two groups. However, the HCQ-treated group were more obese $(P=0.014)$ and had significantly lower LDL levels $(P=0.004)$ while having higher rates of obesity.

In addition, patients treated with HCQ also received MTX $(P=0.016)$, sulfalazine $(P<0.001)$ and biological agents $(P<0.001)$ more often than the non-treated group. Only 6 patients were treated with azathioprine, most in the non-treated group.

The patients' characteristics for patients treated with $400 \mathrm{mg}$ per day and $200 \mathrm{mg}$ a day of HCQ vs the nontreated group are presented in Table 2.

Patients treated with a dose of $200 \mathrm{mg} /$ day of HCQ were younger, had higher levels of HDL and were treated more with sulfasalazine and biological agents than nontreated patients.

Patients treated with $400 \mathrm{mg} /$ day of HCQ were younger, had lower CRP and LDL levels and had shorter disease duration. They suffered more from HTN and obesity and were treated more with sulfasalazine, leflunomide and biological agents than non-treated patients.

Of the HCQ-treated patients, 32 (13.3\%) suffered from any cardiovascular events compared to 104 (38.1\%) of the non-treated group. A time dependent Cox- regression of these outcomes is presented in Table 3. Treatment with HCQ had a significant protective effect for any cardiovascular event with $\mathrm{HR}=0.456$ (CI 0.287 to 0.726 ).

The effects of HCQ treatment on arterial events only are shown in Table 4. Treatment with HCQ had a significant protective effect for arterial events with $\mathrm{HR}=$ 0.461 (CI 0.274 to 0.778 ).

The effects of HCQ treatment on venous events only are shown in Table 5. Treatment with HCQ had a significant protective effect for venous thrombotic events with $\mathrm{HR}=0.386$ (CI 0.155 to 0.961$)$.

We examined the effects of HCQ treatment on mortality. Among the study patients, 159 died (about 31\%) before 2013. The mortality rate in the HCQ-treated group was $22.4 \%$ compared to $38.5 \%$ among the non-treated group. However, a Cox regression with time dependent covariate of HCQ treatment showed no significant protective effect of HCQ treatment for mortality- HR = $0.85195 \%$ CI 0.589 to 1.230 .

Age $(\mathrm{HR}=1.03695 \% \mathrm{CI} 1.020$ to 1.053$)$ and CRP levels ( $\mathrm{HR}=1.12395 \%$ CI 1.077 to 1.171 ) were a significant risk factor for mortality while obesity $(\mathrm{HR}=0.49995 \%$ CI 0.305 to 0.817$)$ showed a protective effect. 
Table 1: HCQ treated vs non treated patients' characteristics

\begin{tabular}{|c|c|c|c|}
\hline Characteristic & HCQ treated patients & Non-treated patients & Significance \\
\hline \multicolumn{4}{|l|}{ Demographics } \\
\hline Age $\pm \mathrm{SD}$ (years) & $68.4 \pm 12.8$ & $75 \pm 12.1$ & $P<0.001$ \\
\hline Gender $(\%$ female $)$ & $187(77.6 \%)$ & $209(76.6 \%)$ & $P=0.916$ \\
\hline \multicolumn{4}{|l|}{ Disease severity markers } \\
\hline CRP (IQR) (mg/dl) & $2.21(0.6-2.7)$ & $3.23(0.69-3.3)$ & $P=0.030$ \\
\hline RF (IQR) (IU/ml) & $180.55(5-169)$ & $177.45(5-158)$ & $P=0.932$ \\
\hline Anti-CCP (IQR) (IU/ml) & $165.06(4-250)$ & $118.03(3.3-250)$ & $P=0.383$ \\
\hline Disease duration (years) & $11.3 \pm 7.1$ & $13.5 \pm 9.1$ & $P=0.002$ \\
\hline \multicolumn{4}{|l|}{ Cardio-vascular risk factors } \\
\hline HTN & $124(51.5 \%)$ & $164(60.1 \%)$ & $P=0.051$ \\
\hline Diabetes & $98(40.8 \%)$ & $117(42.9 \%)$ & $P=0.363$ \\
\hline Hemoglobin A1C level $\pm \mathrm{SD}(\%)$ & $7.1 \pm 1$ & $7.4 \pm 1.1$ & $P=0.114$ \\
\hline Smoking & $66(27.4 \%)$ & $59(21.6 \%)$ & $P=0.149$ \\
\hline Obesity & $73(30.3 \%)$ & $56(20.5 \%)$ & $P=0.014$ \\
\hline Previous cardiovascular disease & $31(12.9 \%)$ & $22(8.1 \%)$ & $P=0.082$ \\
\hline Statin use & $115(47.7 \%)$ & $120(44.0 \%)$ & $P=0.425$ \\
\hline Anti-aggregation therapy & $90(37.3 \%)$ & $113(41.4 \%)$ & $P=0.367$ \\
\hline \multicolumn{4}{|l|}{ Lipid profile } \\
\hline $\mathrm{LDL} \pm \mathrm{SD}(\mathrm{mg} / \mathrm{dl})$ & $100.2 \pm 28.8$ & $107.8 \pm 29$ & $P=0.004$ \\
\hline $\mathrm{HDL} \pm \mathrm{SD}(\mathrm{mg} / \mathrm{dl})$ & $57.3 \pm 16.7$ & $55.0 \pm 15.8$ & $P=0.476$ \\
\hline Triglyceride $\pm \mathrm{SD}(\mathrm{mg} / \mathrm{dl})$ & $132.4 \pm 62.1$ & $134.6 \pm 53.8$ & $P=0.806$ \\
\hline \multicolumn{4}{|l|}{ Other treatment } \\
\hline Azathioprine & $1(0.4 \%)$ & $5(1.8 \%)$ & $P=0.221$ \\
\hline Sulfasalazine & $75(31.1 \%)$ & $35(12.8 \%)$ & $P<0.001$ \\
\hline Prednisone & $192(79.2 \%)$ & $198(72.5 \%)$ & $P=0.078$ \\
\hline MTX & $154(63.9 \%)$ & $145(53.1 \%)$ & $P=0.016$ \\
\hline NSAIDs (constant therapy) & $15(6.2 \%)$ & $20(7.3 \%)$ & $P=0.726$ \\
\hline Leflunomide & $17(7.1 \%)$ & $10(3.7 \%)$ & $P=0.112$ \\
\hline Biological treatment & $59(24.5 \%)$ & $32(11.7 \%)$ & $P<0.001$ \\
\hline
\end{tabular}

$\mathrm{SD}=$ standard deviation, $\mathrm{IQR}=$ interquartile range, $\mathrm{CRP}=\mathrm{C}$-reactive protein, $\mathrm{RF}=$ rheumatic factor, $\mathrm{HTN}=$ hypertension, $\mathrm{LDL}=$ low density lipoprotein, $\mathrm{HDL}=$ high density lipoprotein, $\mathrm{MTX}=$ Methotrexate, NSAIDs=non-steroidal antiinflammatory drug.

In addition we examined the effects of HCQ treatment dose on any cardiovastular disease. We constructed a regression model for patients treated with a dose of $400 \mathrm{mg} /$ day vs non- treated patients and patients treated with $200 \mathrm{mg}$ /day of HCQ vs non-treated patients.

We found that HCQ treatment with $400 \mathrm{mg} /$ day dose showed a significant protective effect for any cardiovascular events (HR $=0.43295 \%$ CI 0.243 to 0.768 ). The protective effect of the higher dose of 400 $\mathrm{mg}$ /day of HCQ was also significant for arterial events $(\mathrm{HR}=0.43395 \% \mathrm{CI} 0.227$ to 0.827$)$ but not for venous thrombotic events or mortality.
However, the HCQ treatment with a dose of $200 \mathrm{mg} /$ day showed no significant protective effect for any cardiovascular disease ( $\mathrm{HR}=0.66595 \%$ CI 0.349 to 1.269). This dose of HCQ also showed no significant protective events for arterial events, venous thrombotic events and mortality.

\section{DISCUSSION}

These findings suggest that HCQ for treating rheumatoid arthritis significantly reduces the risk for cardiovascular morbidity. Patients who received $400 \mathrm{mg}$ a day of HCQ had a lower incidence any cardiovascular 
Table 2: Non-treated patients vs patients treated with $400 \mathrm{mg} / \mathrm{day}$ and $200 \mathrm{mg} / \mathrm{day}$ dose of HCQ characteristics

\begin{tabular}{|c|c|c|c|c|c|}
\hline Characteristic & $\begin{array}{l}\text { Non-treated } \\
\text { patients }\end{array}$ & $\begin{array}{c}\text { HCQ Treated } \\
400 \mathrm{mg} / \mathrm{day}\end{array}$ & $\begin{array}{c}\text { Significance } \\
(400 \text { mg vs } \\
\text { non-treated })\end{array}$ & $\begin{array}{c}\text { HCQ Treated } \\
200 \text { mg/day }\end{array}$ & $\begin{array}{c}\text { Significance } \\
\text { (200 mg vs } \\
\text { non-treated) }\end{array}$ \\
\hline \multicolumn{6}{|l|}{ Demographics } \\
\hline Age $\pm \mathrm{SD}$ (years) & $75 \pm 12.1$ & $66.6 \pm 12.7$ & $P<0.001$ & $71.6 \pm 12.2$ & $P=0.028$ \\
\hline Gender ( $\%$ female $)$ & $209(76.6 \%)$ & $120(76.4 \%)$ & $P=0.99$ & $67(79.8 \%)$ & $P=0.345$ \\
\hline \multicolumn{6}{|l|}{ Disease severity markers } \\
\hline $\mathrm{CRP}(\mathrm{mg} / \mathrm{dl})$ & $3.23 \mathrm{SD}=7$ & $2.15 \mathrm{SD}=3.2$ & $P=0.025$ & $2.3 \mathrm{SD}=2.98$ & $P=0.244$ \\
\hline RF (IU/ml) & $\begin{array}{c}177.45 \\
\mathrm{SD}=396\end{array}$ & $\begin{array}{c}200.7 \\
\mathrm{SD}=429\end{array}$ & $P=0.59$ & $142.9 \mathrm{SD}=302$ & $P=0.473$ \\
\hline Anti-CCP (IU/ml) & $\begin{array}{c}118.03 \\
\mathrm{SD}=192\end{array}$ & $\begin{array}{c}178.9 \\
\mathrm{SD}=209\end{array}$ & $P=0.341$ & $146 \mathrm{SD}=180.6$ & $P=0.663$ \\
\hline Disease duration (years) & $13.5 \pm 9.1$ & $10.8 \pm 6.5$ & $P<0.001$ & $12.3 \pm 8.2$ & $P=0.272$ \\
\hline HTN & $164(60.1 \%)$ & $76(48.4 \%)$ & $P=0.021$ & $48(57.1 \%)$ & $P=0.703$ \\
\hline Diabetes & $117(42.9 \%)$ & $69(43.9 \%)$ & $P=0.084$ & $29(34.9 \%)$ & $P=0.206$ \\
\hline Hemoglobin A1C level \pm SD (\%) & $7.4 \pm 1.1$ & $7.1 \pm 0.96$ & $P=0.043$ & $7.2 \pm 1.1$ & $P=0.319$ \\
\hline Smoking & $59(21.6 \%)$ & $43(27.4 \%)$ & $P=0.196$ & $23(27.4 \%)$ & $P=0.30$ \\
\hline Obesity & $56(20.5 \%)$ & $47(29.9 \%)$ & $P=0.034$ & $26(31 \%)$ & $P=0.054$ \\
\hline Previous cardiovascular disease & $22(8.1 \%)$ & $21(13.4 \%)$ & $P=0.095$ & $10(11.9 \%)$ & $P=0.280$ \\
\hline Statin use & $120(44.0 \%)$ & $74(47.1 \%)$ & $P=0.547$ & $41(48.8 \%)$ & $P=0.454$ \\
\hline Anti-aggregation therapy & $113(41.4 \%)$ & $61(38.9 \%)$ & $P=0.612$ & $29(34.5 \%)$ & $P=0.308$ \\
\hline $\mathrm{LDL} \pm \mathrm{SD}(\mathrm{mg} / \mathrm{dl})$ & $107.8 \pm 29$ & $98.8 \pm 27.1$ & $P=0.002$ & $102.7 \pm 31.6$ & $P=0.173$ \\
\hline $\mathrm{HDL} \pm \mathrm{SD}(\mathrm{mg} / \mathrm{dl})$ & $55.0 \pm 15.8$ & $56.2 \pm 16.6$ & $P=0.475$ & $59.1 \pm 16.8$ & $P=0.047$ \\
\hline Triglyceride \pm SD $(\mathrm{mg} / \mathrm{dl})$ & $134.6 \pm 53.8$ & $133.1 \pm 65$ & $P=0.806$ & $131 \pm 56.6$ & $P=0.601$ \\
\hline \multicolumn{6}{|l|}{ Other treatment } \\
\hline Azathioprine & $5(1.8 \%)$ & $0(0 \%)$ & $P=0.991$ & $1(1.2 \%)$ & $P=0.999$ \\
\hline Sulfasalazine & $35(12.8 \%)$ & $52(33.1 \%)$ & $P<0.001$ & $23(27.4 \%)$ & $P=0.004$ \\
\hline Prednisone & $198(72.5 \%)$ & $127(80.9 \%)$ & $P=0.062$ & $65(77.4 \%)$ & $P=0.478$ \\
\hline MTX & $145(53.1 \%)$ & $99(63.1 \%)$ & $P=0.055$ & $55(65.5 \%)$ & $P=0.059$ \\
\hline NSAIDs (constant therapy) & $20(7.3 \%)$ & $9(5.7 \%)$ & $P=0.690$ & $6(7.1 \%)$ & $P=0.999$ \\
\hline Leflunomide & $10(3.7 \%)$ & $16(10.2 \%)$ & $P=0.010$ & $1(1.2 \%)$ & $P=0.469$ \\
\hline Biological treatment & $32(11.7 \%)$ & $35(22.3 \%)$ & $P<0.001$ & $18(21.4 \%)$ & $P=0.007$ \\
\hline
\end{tabular}

events as well as arterial events(MI and stroke), while a dose of $200 \mathrm{mg}$ a day of HCQ showed no significant protective effect. Furthermore, HCQ treatment had some effect on mortality rates, but it was not significant after the regression model was introduced. There was no significant effect of HCQ treatment duration on mortality. These effects were independent of other RA treatments evaluated.

This study shows a potential protective effect of HCQ on cardiovascular morbidity among RA patients. Cardiovascular disease is a grave concern for RA patients who are 1.5 times more likely to suffer from MI or stroke than the general population $[19,20]$. The current strategy used to combat this risk includes adequate control of disease activity and addressing cardiovascular risk factors. Our findings suggest the possibility of repurposing the use of HCQ to reduce cardiovascular morbidity among RA patients. This could add additional clinical considerations for the physician in the choice of treatment for patients with RA. This is a preliminary study and additional research is needed to evaluate this effect.

The protective effect of HCQ demonstrated in this analysis is in line with two previous studies among lupus 
Table 3: Cox regression with time-dependent covariate of HCQ treated patients vs non-treated

\begin{tabular}{lcccc}
\hline & & & \multicolumn{2}{c}{$\mathbf{9 5 . 0 \%}$ CI for HR } \\
\cline { 5 - 5 } & Significance & HR & Lower & Upper \\
\hline Treatment & 0.001 & 0.456 & 0.287 & 0.726 \\
Age & 0.037 & 1.019 & 1.001 & 1.036 \\
Disease length & 0.043 & 0.971 & 0.944 & 0.999 \\
CRP (mg/dl) & 0.000 & 1.108 & 1.053 & 1.167 \\
LDL & 0.000 & 0.988 & 0.981 & 0.995 \\
Obesity & 0.509 & 0.859 & 0.548 & 1.348 \\
Sulfasalazine treatment & 0.711 & 0.902 & 0.524 & 1.553 \\
MTX treatment & 0.103 & 0.722 & 0.489 & 1.068 \\
Use of biological agents & 0.364 & 0.726 & 0.364 & 1.449 \\
\hline
\end{tabular}

Outcome of any Cardiovascular disease. HR -Hazard Ratio.

Table 4: Cox regression with time-dependent covariate of HCQ treated patients vs non-treated

\begin{tabular}{lcccc} 
& & & \multicolumn{2}{c}{$\mathbf{9 5 . 0 \%}$ CI for HR } \\
\cline { 5 - 5 } & Significance & HR & Lower & Upper \\
\hline Treatment & 0.004 & 0.461 & 0.274 & 0.778 \\
Age & 0.176 & 1.013 & 0.994 & 1.033 \\
Disease length & 0.034 & 0.964 & 0.932 & 0.997 \\
CRP (mg/dl) & $>0.001$ & 1.122 & 1.060 & 1.188 \\
LDL & 0.001 & 0.986 & 0.978 & 0.994 \\
Obesity & 0.697 & 0.905 & 0.546 & 1.499 \\
Sulfasalazine treatment & 0.328 & 0.719 & 0.372 & 1.391 \\
MTX treatment & 0.196 & 0.746 & 0.478 & 1.164 \\
Use of biological agents & 0.326 & 0.664 & 0.293 & 1.503 \\
\hline
\end{tabular}

Outcome: Arterial events only (MI, CVA and TIA).

patients $[21,22]$. It is also backed by evidence that HCQ has a positive effect on lipid profiles and diabetes [14-17]. We would like to note that a study published in 2006 by van Halm examined the effect of different combinations of DMARDs and did not show a protective effect for HCQ alone. This might be due to the different study design that examined the use of HCQ separately for only 36 patients [13].

Additional findings not included in the study design are a significant protective effect of MTX on cardiovascular disease. This result is similar to previous research [23].

Some limitations to this study must be taken into account. First, this is retrospective cohort study and several parameters of disease activity were not available for most of the patients, especially the DAS28 score. As a result, some of the differences between the groups could be attributed to variations in disease activity not detected by this analysis. Despite the importance of the DAS2 8 score in clinical assessment, two prospective studies failed to demonstrate a significant correlation between the score and CVD risk [24, 25]. Second, fewer patients received the lower daily dose of $200 \mathrm{mg}$ HCQ than the $400 \mathrm{mg}$ dose, potentially leading to less significant results among these patients. Third, this study was conducted among patients treated at one medical center, which might have caused an unknown selection bias.

The mechanism by which HCQ influences the risk for CVD events has been poorly investigated. Two small studies showed an improvement in arthrosclerosis among SLE patients [26, 27]. while other studies did not show this effect $[28,29]$. In addition, a recent study suggests that HCQ possesses certain anti-platelet properties through the arachidonic acid pathway [30].

In conclusion, RA patients are at significant risk for cardiovascular disease and better measures are needed to cope with this hazard. This study suggests that HCQ, a commonly used and relatively safe drug, has a significant protective effect against cardiovascular mortality. This finding provides an additional clinical consideration for the attending physician in the choice of appropriate treatment for patients with RA. 
Table 5: Cox regression with time-dependent covariate of HCQ treated patients vs non-treated

\begin{tabular}{lcrrr} 
& & & \multicolumn{2}{c}{$\mathbf{9 5 . 0 \%}$ CI for HR } \\
\cline { 5 - 5 } & Significance & HR & Lower & Upper \\
\hline Treatment & 0.041 & 0.386 & 0.155 & 0.961 \\
Age & 0.040 & 1.036 & 1.002 & 1.071 \\
Disease length & 0.842 & 1.004 & 0.964 & 1.046 \\
CRP (mg/dl) & 0.043 & 1.094 & 1.003 & 1.194 \\
LDL & 0.106 & 0.990 & 0.978 & 1.002 \\
Obesity & 0.523 & 0.758 & 0.325 & 1.772 \\
Sulfasalazine treatment & 0.259 & 1.629 & 0.698 & 3.799 \\
MTX treatment & 0.318 & 0.701 & 0.349 & 1.408 \\
Use of biological agents & 0.511 & 0.655 & 0.185 & 2.314 \\
\hline
\end{tabular}

Outcome: Venous events only (DVT and PE).

\section{MATERIALS AND METHODS}

\section{Study design}

This was a retrospective cohort study among RA patients treated at Meir Medical Center in Kfar Saba, Israel from 2003 through 2013. All data were obtained manually by reviewing patient histories, discharge summaries and medical records using the hospital electronic archive. The Institutional Ethics Committee approved the study.

Inclusion criteria were a diagnosis of rheumatoid arthritis, age 18 years or older and sufficient follow up information. A total of 514 RA patients met the inclusion criteria. The patients were divided into two groups. The treated group consisted of 241 patients who were treated with HCQ at some point in the course of their disease. The non-treated group consisted of 273 patients who had never received the drug.

\section{Confounding factors}

Data were collected regarding factors that could confound the effect of HCQ treatment on cardiovascular morbidity. The confounding factors were categorized as 1) demographic characteristics, 2) disease severity indicators, 3) common cardiovascular risk factors and protective treatment and 4) other treatment prescribed for RA.

The use of biological agents for the treatment of RA has been growing in Israel. However, many patients are still treated with traditional DMARDs alone. The small treatment rates precluded separate analysis of each biological drug and they were grouped together for statistical analysis.

\section{End points}

Patient files were examined for incidence of cardiovascular events. For the non-treated group, only events that occurred after the diagnosis of RA were recorded. For the treated group, the events recorded occurred after initiation of HCQ treatment.

Data regarding arterial events including myocardial infarction (MI), and cerebrovascular events including stroke and transient ischemic attacks (TIA) were collected, as well as venous thrombosis events, including deep venous thrombosis (DVT) and pulmonary embolism (PE). A few ischemic colitis events and peripheral artery disease were recorded. The secondary study endpoint was any cause mortality.

\section{Statistical analysis}

To evaluate the difference between patients treated with HCQ and those who did not, we applied the T test for continuous variables and chi-square test for categorical variables.

Multivariate models were adjusted for age and other known risk factor for cardiovascular disease. We used the time-dependent Cox proportional hazards regression model to estimate the risk for $\mathrm{CV}$ event among rheumatoid arthritis patients according to HCQ use. Hazard ratios (HRs) and 95\% confidence intervals (CIs) were evaluated to determine the association between the risk of $\mathrm{CV}$ event and HCQ use.

As not all the patients started to use HCQ from the beginning of the follow-up period, the drug use varied over time, it was measured as a time-dependent covariate in the Cox proportional hazard model. We used timedependent variables for present age and present disease years as well.

We performed three different comparisons: treated versus non-treated patients, patients treated with $200 \mathrm{mg} /$ day versus non-treated patients, and patients treated with $400 \mathrm{mg} /$ day versus non-treated patients.

The SPSS software (Version 24.0, IBM SPSS Statistics) was used for data management and statistical analysis. A 2 -sided $P$ value $<.05$ was considered statistically significant. 


\section{Ethical approval}

The study was approved by the Meir Medical Center Ethics Committee - decision MMC-0178-12.

\section{Author contributions}

The authors Michael Shapiro and Yair Levy had equal and substantial contribution to the research, including the design, acquisition of data and data analyzing.

\section{CONFLICTS OF INTEREST} disclose.

We declare that we have no conflicts of interest to

\section{FUNDING}

This research received no specific grant from any funding agency in the public, commercial or not-for-profit sectors.

\section{REFERENCES}

1. Helmick CG, Felson DT, Lawrence RC, Gabriel S, Hirsch R, Kwoh CK, Liang MH, Kremers HM, Mayes MD, Merkel PA. Estimates of the prevalence of arthritis and other rheumatic conditions in the United States: Part I. Arthritis Rheum. 2008; 58:15-25.

2. Turesson C, O'Fallon W, Crowson C, Gabriel S, Matteson E. Extra-articular disease manifestations in rheumatoid arthritis: incidence trends and risk factors over 46 years. Ann Rheum Dis. 2003; 62:722-7.

3. Turesson C, Jacobsson L, Sturfelt G, Matteson E, Mathsson L, Rönnelid J. Rheumatoid factor and antibodies to cyclic citrullinated peptides are associated with severe extraarticular manifestations in rheumatoid arthritis. Ann Rheum Dis. 2007; 66:59-64.

4. Del Rincón I, Williams K, Stern MP, Freeman GL, Escalante A. High incidence of cardiovascular events in a rheumatoid arthritis cohort not explained by traditional cardiac risk factors. Arthritis Rheum. 2001; 44:2737-45.

5. Van Doornum S, McColl G, Wicks I. Accelerated atherosclerosis: an extraarticular feature of rheumatoid arthritis? Arthritis Rheum. 2002; 46:862-73.

6. Levi EH, Watad A, Whitby A, Tiosano S, Comaneshter D, Cohen AD, Amital H. Coexistence of ischemic heart disease and rheumatoid arthritis patients - a case control study. Autoimmunity reviews. 2016; 15:393-6.

7. del Rincón I, Williams K, Stern MP, Freeman GL, O'Leary DH, Escalante A. Association between carotid atherosclerosis and markers of inflammation in rheumatoid arthritis patients and healthy subjects. Arthritis Rheum. 2003; 48:1833-40.
8. Aubry MC, Maradit-Kremers H, Reinalda MS, Crowson CS, Edwards WD, Gabriel SE. Differences in atherosclerotic coronary heart disease between subjects with and without rheumatoid arthritis. The Journal of rheumatology. 2007; 34:937-42.

9. Goodson NJ, Symmons DP, Scott DG, Bunn D, Lunt M, Silman AJ. Baseline levels of c-reactive protein and prediction of death from cardiovascular disease in patients with inflammatory polyarthritis: A ten-year followup study of a primary care-based inception cohort. Arthritis Rheum. 2005; 52:2293-9.

10. Peters M, Symmons D, McCarey D, Dijkmans B, Nicola P, Kvien T, McInnes I, Haentzschel H, Gonzalez-Gay M, Provan S. EULAR evidence-based recommendations for cardiovascular risk management in patients with rheumatoid arthritis and other forms of inflammatory arthritis. Ann Rheum Dis. 2010; 69:325-31.

11. Singh JA, Furst DE, Bharat A, Curtis JR, Kavanaugh AF, Kremer JM, Moreland LW, O'Dell J, Winthrop KL, Beukelman T. 2012 Update of the 2008 American College of Rheumatology recommendations for the use of diseasemodifying antirheumatic drugs and biologic agents in the treatment of rheumatoid arthritis. Arthritis Care Res. 2012; 64:625-39.

12. Saag KG, Teng GG, Patkar NM, Anuntiyo J, Finney C, Curtis JR, Paulus HE, Mudano A, Pisu M, Elkins-Melton M. American College of Rheumatology 2008 recommendations for the use of nonbiologic and biologic disease-modifying antirheumatic drugs in rheumatoid arthritis. Arthritis Care Res. 2008; 59:762-84.

13. van Halm VP, Nurmohamed MT, Twisk JW, Dijkmans BA, Voskuyl AE. Disease-modifying antirheumatic drugs are associated with a reduced risk for cardiovascular disease in patients with rheumatoid arthritis: a case control study. Arthritis Res Ther. 2006; 8:R151.

14. Wallace DJ, Metzger AL, Stecher VJ, Turnbull BA, Kern PA. Cholesterol-lowering effect of hydroxychloroquine in patients with rheumatic disease: reversal of deleterious effects of steroids on lipids. The American journal of medicine. 1990; 89:322-6.

15. Morris SJ, Wasko MC, Antohe JL, Sartorius JA, Kirchner HL, Dancea S, Bili A. Hydroxychloroquine use associated with improvement in lipid profiles in rheumatoid arthritis patients. Arthritis Care Res. 2011; 63:530-4.

16. Kerr G, Aujero M, Richards J, Sayles H, Davis L, Cannon G, Caplan L, Michaud K, Mikuls T. Associations of hydroxychloroquine use with lipid profiles in rheumatoid arthritis: Pharmacologic implications. Arthritis Care Res. 2014; 66:1619-26.

17. Wasko MC, Hubert HB, Lingala VB, Elliott JR, Luggen ME, Fries JF, Ward MM. Hydroxychloroquine and risk of diabetes in patients with rheumatoid arthritis. JAMA. 2007; 298:187-93.

18. Ruiz-Irastorza G, Ramos-Casals M, Brito-Zeron P, Khamashta MA. Clinical efficacy and side effects of 
antimalarials in systemic lupus erythematosus: a systematic review. Ann Rheum Dis. 2010; 69:20-8.

19. Solomon DH, Karlson EW, Rimm EB, Cannuscio CC, Mandl LA, Manson JE, Stampfer MJ, Curhan GC. Cardiovascular morbidity and mortality in women diagnosed with rheumatoid arthritis. Circulation. 2003; 107:1303-7.

20. Aviña-Zubieta JA, Choi HK, Sadatsafavi M, Etminan M, Esdaile JM, Lacaille D. Risk of cardiovascular mortality in patients with rheumatoid arthritis: A meta-analysis of observational studies. Arthritis Care Res. 2008; 59:1690-7.

21. Erkan D, Yazici Y, Peterson M, Sammaritano L, Lockshin M. A cross-sectional study of clinical thrombotic risk factors and preventive treatments in antiphospholipid syndrome. Rheumatology (Oxford). 2002; 41:924-9.

22. Ruiz-Irastorza G, Egurbide M, Pijoan J, Garmendia M, Villar I, Martinez-Berriotxoa A, Erdozain J, Aguirre C. Effect of antimalarials on thrombosis and survival in patients with systemic lupus erythematosus. Lupus. 2006; 15:577-83.

23. Choi HK, Hernán MA, Seeger JD, Robins JM, Wolfe F. Methotrexate and mortality in patients with rheumatoid arthritis: a prospective study. The Lancet. 2002; 359:1173-7.

24. Radovits BJ, Popa-Diaconu DA, Popa C, Eijsbouts A, Laan RF, Van Riel PL, Fransen J. Disease activity as a risk factor for myocardial infarction in rheumatoid arthritis. Ann Rheum Dis. 2009; 68:1271-6.
25. Arts EE, Fransen J, den Broeder AA, Popa CD, van Riel PL. The effect of disease duration and disease activity on the risk of cardiovascular disease in rheumatoid arthritis patients. Ann Rheum Dis. 2015; 74:998-1003.

26. Selzer F, Sutton-Tyrrell K, Fitzgerald S, Tracy R, Kuller L, Manzi S. Vascular stiffness in women with systemic lupus erythematosus. Hypertension. 2001; 37:1075-82.

27. Tanay A, Leibovitz E, Frayman A, Zimlichman R, Gavish D. Vascular elasticity of systemic lupus erythematosus patients is associated with steroids and hydroxychloroquine treatment. Ann N Y Acad Sci. 2007; 1108:24-34.

28. Manzi S, Selzer F, Sutton-Tyrrell K, Fitzgerald SG, Rairie JE, Tracy RP, Kuller LH. Prevalence and risk factors of carotid plaque in women with systemic lupus erythematosus. Arthritis Rheum. 1999; 42:51-60.

29. Ahmad Y, Shelmerdine J, Bodill H, Lunt M, Pattrick M, Teh L, Bernstein R, Walker M, Bruce I. Subclinical atherosclerosis in systemic lupus erythematosus (SLE): the relative contribution of classic risk factors and the lupus phenotype. Rheumatology (Oxford). 2007; 46:983-8.

30. Achuthan S, Ahluwalia J, Shafiq N, Bhalla A, Pareek A, Chandurkar N, Malhotra S. Hydroxychloroquine's Efficacy as an Antiplatelet Agent Study in Healthy Volunteers A Proof of Concept Study. J Cardiovasc Pharmacol Ther. 2015; 20:174-80. 